\title{
Impacts of cultural risk factors on project success in the UAE construction industry
}

\author{
M. Al Hasani a ${ }^{\text {G.A Tularam }}{ }^{\text {b }}$ and M. Regan ${ }^{a}$ \\ ${ }^{a}$ Faculty of Society \& Design, Bond University, Queensland \\ ${ }^{b}$ Environmental Futures Research Institute, Griffith University, Queensland \\ Email : a.tularam@griffith.edu.au
}

\begin{abstract}
Industrial risk management is an area of interest in business and management research. Construction is a risky and dynamic industry that is particularly prone to a variety of risks and uncertainties. The nature of these risks may depend on particular projects and can significantly vary from country to country. Therefore, the essential goal of research in identifying and characterising risks in construction is two-fold, involving (1) the identification and characterisation of any general trends, risks and mitigating strategies that are common in different countries and extend over a variety of construction projects in one or more countries; and (2) the identification and characterisation of any particular construction risk in a given country or even for a given project and understanding any variability of risks for different projects or countries. The detailed analysis of risks and risk factors associated with both these aims is essential for the successful development of the construction industries that constitute a significant part of the world economy.

The major focus of this paper is the analysis and characterization of cultural risks in the construction industry in the United Arab Emirates (UAE). The unprecedented construction boom in the UAE since 1971 has caused rapid and extensive growth in its construction industry. However, this rapid growth and its sustainability are threatened by a variety of factors including significant cultural issues associated with the traditional Arabic culture and the unprecedented diversity of the workforce in the UAE, as more than $80 \%$ of workers are expatriates from different parts of the world. This creates a unique business environment in the country whose successful development largely underpins the economic progress in the Middle East and elsewhere.
\end{abstract}

The analysis of cultural risks in the UAE construction industry was conducted using a specially designed and validated survey instrument. There were 237 participants of the study, all holding senior engineering or managerial positions in companies associated with the construction industry in the UAE. The analysis was based on the identification and quantitative characterization of the constructs associated with the cultural risk factors and generalized structural equation modelling to characterize the direct and indirect effects of these constructs on the success of construction projects. All outcomes were adjusted to socioeconomic and company variables.

Among the mediating constructs, External Risks (involving corruption, government regulations, market demand and differences between stakeholders) and Communication (involving communication issues between the parties to the contract, employers and employees) dominated Internal Risks, which were generally perceived as less important. The cultural factors produced significant impacts on these mediating constructs that, in turn, affected project success.

Only two UAE cultural aspects were found to have positive impact on project success. These were differences in educational backgrounds and a more stringent attitude to time among Emiratis that people from Western countries. All other specific cultural aspects were found to have significant negative impacts.

The two different constructs associated with the existing cultural aspects in UAE were identified as UAE Culture and Cultural Diversity. Both of these constructs were shown to have significant impacts on project success, but only through the mediation of the other three constructs of Internal Risks, External Risks and Communication. In particular, it was demonstrated that the cultural diversity issues have twice as strong an impact on the success of construction projects in UAE than the general cultural issues in UAE. Therefore, the issues of cultural diversity should be given priority in any attempts to mediate construction risks and improve productivity in the industry.

Keywords: Construction industry in the UAE, construction risks, cultural risks, UAE culture, cultural diversity 


\section{INTRODUCTION}

As of May 2016, the pipeline of construction projects in the pre-execution stage in the Gulf Cooperation Council (GCC) countries amounted to more than US\$2 trillion, with the UAE capturing around $34.84 \%$ of the total value of these projects (Deloitte, 2016). This is a reflection of the decades of the unprecedented construction boom in the GCC countries, including the UAE (Deloitte, 2016).

The rapidly developing construction industry requires adequate identification, consideration and the resolution of a variety of issues related to productivity, labour, resources and technology, socioeconomic factors, and a wide spectrum of cultural, economic and financial matters and traditions. Any of these factors are capable of creating significant barriers and risks for projects and productivity growth in the construction industries of the GCC countries. The identification, analysis and characterization of any such barriers and risks as well as the development of effective mitigating strategies are essential for the continuing growth of the industry.

Industrial risk is typically defined as a potential occurrence (an event, condition or circumstance) that is uncertain in likelihood and consequence and, if it occurs, could affect the ability to achieve one or more planned objectives (Harvett, 2013; Loosemore et al., 2006; PMI, 2013). Some sources consider risks as potential occurrences that have both negative and positive impacts on the expected objectives (PMI, 2013; Ratherford, 2002). Although this is somewhat at variance with the common meaning of the word 'risk' as a possibility of something unpleasant or unwelcome, in this paper we will adopt this wider definition of risk. This will be consistent with the conducted modelling in which the considered risks and risk factors might have positive or negative impacts on project success.

Construction is one of the most risky, difficult and dynamic industries (Hwang et al., 2017) as, due to its financial intensity, complex procedures, long project durations, risky environment and partner relationships, this industry is prone to a variety of risks (Panthi et al., 2009). There are also vast variations in the risks that exist in in construction industries in different countries and cultures (Al-Yahya, 2009; Assaf \& Al-Hejji, 2006; Deloitte, 2016; El-Sayegh, 2008; Odongo et al., 2012; Randeree and Chaudhry, 2012). In particular, Odongo et al. (2012) show that differences in values, norms and literacy rates are likely to have the greatest impact on pricing decisions (which are directly relevant to contractual, financial and economic risks).

The UAE is the second largest economy among the GCC countries (after Saudi Arabia) (Deloitte, 2016) and has the second largest value of construction output in the world as of 2015 (AECOM, 2016). This is an illustration of the importance of the UAE for economic development in the Middle East. At the same time, the UAE has unique economic and cultural characteristics in comparison to other countries in the Middle East. This uniqueness is related to the highly diverse cultural and ethnic mix in the workforce, with expatriates constituting $75 \%$ to $85 \%$ of the total workforce (Al Ariss and Guo, 2016). The detailed understanding and mitigation of any cultural risks are essential to ensure the further growth and rapid development of the UAE construction industry.

Although there is an impressive body of literature concerning risk management in construction industries (see above), the research still represents only the initial steps towards the detailed analysis and characterization of construction risks. This is because few papers in this area use modern analytical methods to adequately identify and characterize causal relationships between the considered variables and/or risk constructs. Some of these papers still had significant deficiencies, such as insufficiently justified model fit (Kim et al., 2009; Liu et al., 2016), while the others did not consider cultural risk constructs (Doloi et al., 2012; Eybpoosh et al., 2011; Sambasivan et al., 2017).

Therefore, the aim of this paper is to conduct the quantitative identification, analysis and modelling of cultural risks in the UAE construction industry on the basis of a questionnaire instrument that has been developed to evaluate such risks. The major focus of the conducted analysis will be on the construction and validation of risk constructs (factors), with the subsequent determination of their direct and indirect effects on project success. We will also provide interpretations and explanations of the obtained outcomes and outline recommendations for possible strategies to better mitigate cultural risks.

\section{CONSTRUCT DEVELOPMENT}

\subsection{Data Sample}

The conducted analysis and statistical modelling were based on the data collected from 237 qualified participants, using the survey instrument specifically designed for the evaluation of risks in the UAE construction industry. The survey was validated using the existing literature on risk management, recommendations from three expert advisors in the field of risk management, and a small pilot study to test the 
AL hasani et al., Impacts of cultural risk factors on project success in the UAE construction Industry

survey, its efficiency, clarity, relevance and completeness. The study included three different participant categories: clients (33 participants), contractors (148 participants) and consultants (56 participants). This selection ensured a reasonable spectrum of opinions coming from different construction parties. The overall sample size was sufficient for the analysis of around 25 relationships in each considered model (Nunnally, 1967).

\subsection{Dependent and Independent Constructs}

The main adopted methodology involved confirmatory factor analysis (CFA) for construct development and generalized structural equation modelling (GSEM) for the determination of causal direct and indirect effects of constructs, numerical and categorical (socioeconomic) variables on construction project success.

Table 1. The developed constructs with the factor loadings for the associated items. Asterisks show the levels of statistical significance of the corresponding factor loadings: $(* * *) p<0.001 ;(* *) 0.001 \leq p<0.01 ;(*) 0.01$ $\leq p<0.05$. Only 2 significant covariance's were identified: Q31.8 $\leftrightarrow \mathrm{Q} 31.9$ and Q31.9 $\leftrightarrow \mathrm{Q} 31.10$.

\begin{tabular}{|c|c|c|}
\hline Construct & Survey Item & Factor Loading \\
\hline \multirow[t]{3}{*}{ Project Success } & Q35: Were project's objectives met? & $0.65 * * *$ \\
\hline & Q38: Was project's scope achieved? & $0.82 * * *$ \\
\hline & Q40: How would you rate the client's satisfaction with the delivery of the project? & $0.80 * * *$ \\
\hline \multirow[t]{4}{*}{ External Risks } & Q29.1: Corrupt government officials demand bribes or unjust rewards & $0.65 * * *$ \\
\hline & Q29.2: Government's inconsistent application of new regulations and laws & $0.48 * * *$ \\
\hline & Q29.12: Inadequate forecast about market demand & $0.70 * * *$ \\
\hline & Q29.13: Differences in work culture, education and values between project stakeholders & $0.39 * * *$ \\
\hline \multirow[t]{4}{*}{ Internal Risks } & Q29.4: High rate of accidents during construction or operation phases & $0.79 * * *$ \\
\hline & Q29.11: Inadequate project planning, budgeting, organizational structure or competence & $0.59 * * *$ \\
\hline & Q29.14: Facing difficulties in hiring and retaining valued and valuable employees & $0.69 * * *$ \\
\hline & Q29.15: Unanticipated design changes and errors in design/drawings & $0.72 * * *$ \\
\hline \multirow[t]{8}{*}{ Communication } & Q31.6: The system of communication about the nature of risks is effective & $0.55 * * *$ \\
\hline & Q31.7: The system of communication about risk mitigation strategies is effective & $0.52 * * *$ \\
\hline & Q31.8: There is a large communication gap between contractor and client & $-0.75^{* * *}$ \\
\hline & Q31.9: There is a large communication gap between contractor and consultant & $-0.22 * *$ \\
\hline & Q31.10: There is a large communication gap between contractor and employees & $-0.56^{* * *}$ \\
\hline & Q31.18: Stakeholder engagement is important in the project & $-0.41 * * *$ \\
\hline & $\begin{array}{l}\text { Q34.3: Reporting and communication between staff and management supports effective risk } \\
\text { management }\end{array}$ & $0.20 *$ \\
\hline & Q34.9: A functional reporting concept has been designed and implemented & $0.27 * *$ \\
\hline \multirow[t]{5}{*}{ UAE Culture } & Q31.1: Emiratis value personal trust as an important ingredient in business transactions & $0.64 * * *$ \\
\hline & Q31.2: Emiratis prefer to do business face to face & $0.58 * * *$ \\
\hline & Q31.3: Emiratis like to get to know the person they are dealing with before they do business & $0.46^{* * *}$ \\
\hline & Q31.4: Attitudes to time in many Western countries are much more relaxed than in the UAE & $-0.43^{* * *}$ \\
\hline & Q31.5: There is a strong vertical hierarchy structure in most Emirate companies & $0.51 * * *$ \\
\hline \multirow{5}{*}{$\begin{array}{l}\text { Cultural } \\
\text { Diversity }\end{array}$} & Q31.14: Various languages affect the project & $0.56 * * *$ \\
\hline & Q31.15: Various educational backgrounds affect the project & $-0.22 *$ \\
\hline & Q31.16: Different ways of thinking affect the project & $0.47 * * *$ \\
\hline & Q31.17: Various decision-making processes affect the project & $0.54 * * *$ \\
\hline & Q31.19: Dispute resolution is important in the project & $0.54 * * *$ \\
\hline
\end{tabular}

The developed constructs, including the dependent construct of Project Success, are presented in Table 1. The validity of these constructs was further confirmed through the Cronbach's alpha analysis and determination of model fits for all CFA models (with $p>0.12$ for the chi-square test, and other goodness of fit (GOF) indices being: RMSEA $>0.065$; CFI $>0.92$, TLI $>0.84$, SRMR $<0.106$, coefficient of determination $(\mathrm{CD})>0.62$, and Cronbach's alpha $>0.58$ ). 
The obtained factor loadings (Table 1) give the quantitative evaluations of the strength of the association between the corresponding items and the constructs, such that the larger the magnitude of a factor loading, the more important is the considered item for the construct. The negative signs of the loadings indicate the opposite directions of the respective items or the opposite direction of the effect of the constructs on the associated items. For example, the negative signs of the factor loadings associated with items Q31.8 - Q31.10 (Table 1) show that the Communication factor score increases with decreasing communication gaps. Therefore, if the Communication factor has a positive effect on Project Success, then the Communication gaps (items Q31.8 Q31.10) must have negative effects on Project Success (which is to be expected).

\section{GSEM MODEL}

As there is a significant possibility that the developed independent constructs could impact on each other (i.e., be correlated with each other), the statistical modelling aimed at the identification and characterization of any mutual impacts between the developed constructs should be based on structural equation modelling (SEM). An SEM model enables not only a reliable characterization of the relationships between numerous correlated variables/constructs, it also enables the visualization of a network of direct and indirect effects where some independent variables or factors impact on the dependent variables or factors through other mediating variables, thus producing indirect effects that are not possible or difficult to consider in any other statistical model.

Because of the presence of categorical variables in the survey data (e.g., gender, education, experience, type of company, etc.) which cannot be considered in a standard SEM (StataCorp, 2015), GSEM modelling in Stata 14 was used. Due to the limitations of the sample size (237 participants), each developed construct was considered in the GSEM model as a latent numerical variable characterized by its factor score obtained from the respective CFA model (Figure 1).

\subsection{Indirect Effects of Cultural Factors}

It can be seen that neither of the two cultural factors has any significant direct effect on Project Success. This is one of the possible reasons for some previous studies overlooking cultural risk factors. However, both of these factors have significant indirect effects on Project Success through the mediating constructs of External and Internal Risks, and Communication (Figure 1). The significant indirect effects together with their regression coefficients (calculated as products of

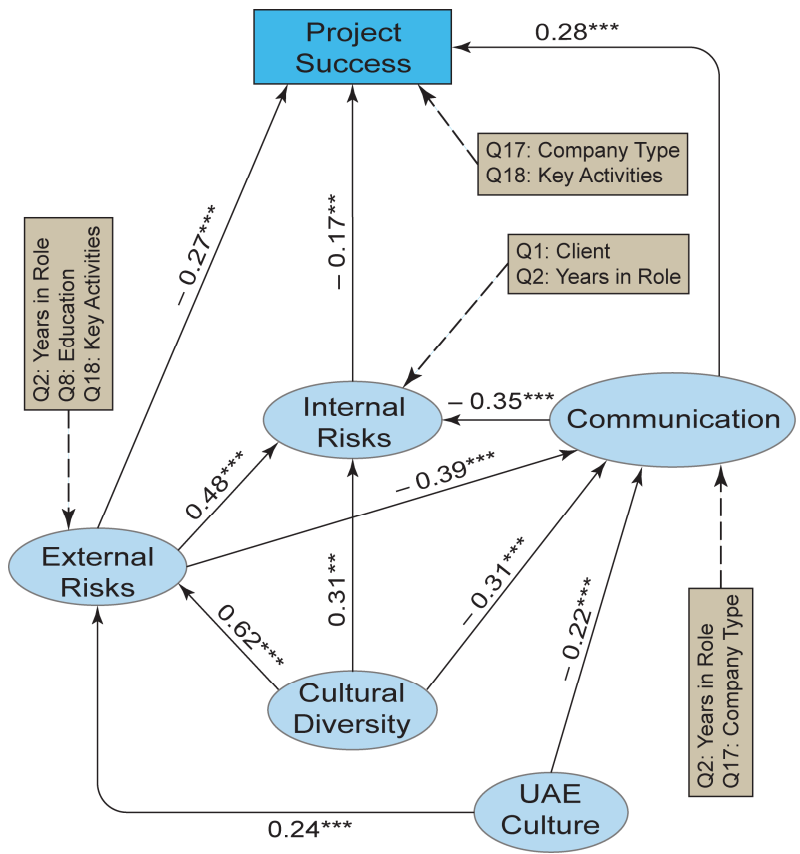

Figure 1. GSEM model illustrating the effects of cultural factors (latent variables) on Project Success.

The regression coefficients are shown only for the significant direct effects between the considered factors.

For simplicity of presentation, the significant measurable variables are grouped into boxes, corresponding to each of the factors these variables act on (see Table 2 for the respective regression coefficients and their $p$-values). Asterisks indicate the levels of statistical significance: $(* * *) p<0.001 ;(* *) 0.001 \leq p<$ 0.01 . the coefficients of the involved direct effects) and $p$-values are listed as follows:

UAE Culture $\rightarrow$ Communication $\rightarrow$ Project Success $(K=-0.062 ; p<0.001)$;

UAE Culture $\rightarrow$ Communication $\rightarrow$ Internal Risks $\rightarrow$ Project Success $(K=-0.013 ; p=0.004)$;

UAE Culture $\rightarrow$ External Risks $\rightarrow$ Project Success $(K=-0.065 ; p<0.001)$;

$\mathrm{UAE}$ Culture $\rightarrow$ External Risks $\rightarrow$ Internal Risks $\rightarrow$ Project Success $(K=-0.020 ; p=0.004)$

UAE Culture $\rightarrow$ External Risks $\rightarrow$ Communication $\rightarrow$ Project Success $(K=-0.026 ; p<0.001)$;

UAE Culture $\rightarrow$ External Risks $\rightarrow$ Communication $\rightarrow$ Internal Risks $\rightarrow$ Project Success $(K=-0.0056 ; p=$ 0.004);

Cultural Diversity $\rightarrow$ Communication $\rightarrow$ Project Success $(K=-0.087 ; p<0.001)$;

Cultural Diversity $\rightarrow$ Communication $\rightarrow$ Internal Risks $\rightarrow$ Project Success $(K=-0.018 ; p=0.004)$; 
Cultural Diversity $\rightarrow$ Internal Risks $\rightarrow$ Project Success $(K=-0.053 ; p=0.004)$;

Cultural Diversity $\rightarrow$ External Risks $\rightarrow$ Project Success $(K=-0.167 ; p<0.001)$;

Cultural Diversity $\rightarrow$ External Risks $\rightarrow$ Internal Risks $\rightarrow$ Project Success $(K=-0.051 ; p=0.004)$;

Cultural Diversity $\rightarrow$ External Risks $\rightarrow$ Communication $\rightarrow$ Project Success $(K=-0.068 ; p<0.001)$;

Cultural Diversity $\rightarrow$ External Risks $\rightarrow$ Communication $\rightarrow$ Internal Risks $\rightarrow$ Project Success $(K=-0.014 ; p$ $=0.004)$.

Table 2. The outcomes of the GSEM model for the Project Success factor and the cultural and mediating constructs, including the regression coefficients for the significant direct effects and their corresponding $p$ values.

\begin{tabular}{|c|c|c|c|c|}
\hline $\begin{array}{l}\text { Response } \\
\text { Variables }\end{array}$ & \multicolumn{2}{|l|}{ Predictor Variables } & $\begin{array}{l}\text { Regression } \\
\text { Coefficient }\end{array}$ & $p$-value \\
\hline \multirow[t]{5}{*}{ Project Success } & \multicolumn{2}{|l|}{ External Risk } & -0.2742 & $<0.001$ \\
\hline & \multicolumn{2}{|l|}{ Internal Risk } & -0.1746 & 0.003 \\
\hline & \multicolumn{2}{|l|}{ Communication } & 0.2789 & $<0.001$ \\
\hline & \multicolumn{2}{|c|}{$\begin{array}{l}\text { Q17: Company Type } \\
\text { (Public versus International, Government and Private) }\end{array}$} & -0.2212 & 0.086 \\
\hline & \multicolumn{2}{|c|}{$\begin{array}{l}\text { Q18: Key Company Activities } \\
\text { (Building, Housing, Infrastructure and Other versus Industrial) }\end{array}$} & 0.1175 & 0.079 \\
\hline \multirow[t]{5}{*}{ External Risks } & \multicolumn{2}{|l|}{ UAE Culture } & 0.244 & $<0.001$ \\
\hline & \multicolumn{2}{|l|}{ Cultural Diversity } & 0.620 & $<0.001$ \\
\hline & \multicolumn{2}{|c|}{ Q8: Education (Everything versus PhD) } & 0.289 & $<0.011$ \\
\hline & \multicolumn{2}{|c|}{ Q2: Years in the Job (from 6 to 15 years versus other) } & -0.122 & 0.034 \\
\hline & \multicolumn{2}{|c|}{$\begin{array}{l}\text { Q18: Key Company Activities } \\
\text { (Building, Housing, Infrastructure, Other versus Industrial) }\end{array}$} & -0.149 & 0.014 \\
\hline \multirow[t]{6}{*}{ Internal Risks } & \multicolumn{2}{|l|}{ External Risk } & 0.4825 & $<0.001$ \\
\hline & \multicolumn{2}{|l|}{ Communication } & -0.345 & $<0.001$ \\
\hline & \multicolumn{2}{|l|}{ Cultural Diversity } & 0.3143 & 0.002 \\
\hline & \multirow[t]{2}{*}{ Q1: Job Title (versus Contractor) } & Consultant & - & 0.129 \\
\hline & & Client & 0.272 & 0.004 \\
\hline & \multicolumn{2}{|c|}{ Q2: Years in the Job (from 6 to 15 years versus other) } & -0.359 & $<0.001$ \\
\hline \multirow[t]{6}{*}{ Communication } & \multicolumn{2}{|l|}{ External Risk } & -0.3919 & $<0.001$ \\
\hline & \multicolumn{2}{|l|}{ UAE Culture } & 0.2230 & $<0.001$ \\
\hline & \multicolumn{2}{|l|}{ Cultural Diversity } & -0.3143 & $<0.001$ \\
\hline & \multicolumn{2}{|c|}{ Q2: Years in the Job (from 6 to 15 years versus other) } & 0.2408 & $<0.001$ \\
\hline & \multicolumn{2}{|l|}{ Q3: Gender (Female versus Male) } & - & 0.185 \\
\hline & \multicolumn{2}{|c|}{ Q17: Company Type (Public versus International, Government and Private) } & -0.2426 & 0.025 \\
\hline
\end{tabular}

The total effects of UAE Culture and Cultural Diversity on Project Success can thus be calculated as the sums of all respective indirect effects:

Total effect of UAE Culture $=-0.192(p<0.001)$; and

Total effect of Cultural Diversity $=-0.458(p<0.001)$.

Importantly, the constructs of UAE Culture and Cultural Diversity have significant and strong effects on Internal Risks, External Risks, and Communication. These effects on Internal Risks and External Risks are positive in that the majority of the cultural diversity and UAE cultural items increase internal and external risks as defined in Table 2. The same cultural constructs have negative impacts on Communication in that the majority of the cultural diversity items and UAE cultural items increase the existing communication gaps and impede communication efficiency.

The total effects of the mediating factors of Internal Risks, External Risks, and Communication on Project Success were:

Total effect of Communication $=0.340(p<0.001)$;

Total effect of External Risks $=-0.484(p<0.001)$; and

Total effect of Internal Risks $=-0.17(p=0.003)$. 


\subsection{Model Fit}

The validity of the developed GSEM model (Figure 1) is confirmed by the respective set of GOF indices: $p=$ 0.82 (for the chi-square test), $\mathrm{RMSEA}<0.001, \mathrm{CFI}=\mathrm{TLI}=1, \mathrm{SRMR}=0.015, \mathrm{CD}=0.62$. These values of the GOF indices demonstrate the exceptional model fit. The indicated value of CD means that the developed model explains around $62 \%$ of the total variance of the involved endogenous variables. This is a good outcome, demonstrating that only about $38 \%$ of the total variable requires consideration of some other variables and/or factors not involved in the model.

\section{DISCUSSION AND CONCLUSIONS}

The fact that both the constructs of Cultural Diversity and UAE Culture do not have direct effects on Project Success but have strong indirect and total effects once again highlight the essential need for the adopted methodology based on the GSEM modelling (Figure 1 and Table 2).

All indirect effects of both the cultural factors on Project Success were negative, as were the total effects - see (1) and (2). Therefore, the Project Success factor score decreases (success is reduced) with increasing scores for UAE Culture and Cultural Diversity. In other words, UAE cultural features and cultural diversity appear to be mostly detrimental for project success in the construction industry. The only exceptions were items Q31.4 and Q31.15 (Table 1), which had negative factor loadings and, thus, had positive impacts on Project Success (unlike all other items associated with the two cultural constructs - Table 1).

For example, item Q31.1 has a positive factor loading in the UAE Culture factor (Table 1). Therefore, study participants who agreed that Emiratis value personal trust tended to disagree that the construction project was successful (because of the negative relationship between UAE Culture and Project Success (1)). This gives rise to a conclusion that Emiratis valuing personal trust in business transactions appears to be detrimental for the success of construction projects (and, thus, for effective risk management). At the same time, because of the significant negative loading for Q31.4 (Table 1), it could be said that more the stringent attitude to time in UAE had a positive impact on Project Success, which was the only identified aspect of the UAE culture beneficial for construction projects. All other aspects of UAE culture, including a preference to do business face-to-face, preferring to have personal knowledge about a business partner, and the strong vertical hierarchy of most Emirate companies appeared to be detrimental for project success and risk management in the UAE construction industry.

The total effect of Cultural Diversity on Project Success is more than two times larger in magnitude than that of UAE Culture (compare equations (1) and (2)). A comparison of equations (3) to (5) further demonstrates that Communication and External Risks are significantly more important for successful risk management than Internal Risks. These comparisons enable the identification of the nine most critical specific risks for the success of construction projects in UAE, as those associated with the three most important constructs of Cultural Diversity, Communication and External Risks, and having the largest factor loadings (Table 1). These are:

- The corruption of government officials;

- Inadequate forecasting of market demand;

- Language diversity;

- Diversity of decision-making processes;

- Lack of effective dispute resolution procedures;

- Large communication gap between the contractor and the client;

- Lack of an effective system for the communication of risks;

- Lack of an effective system for the communication of risk mitigation strategies; and

- Large communication gap between the contractor and the employees.

All of these specific risks are related to cultural diversity either by association or by means of significant direct or indirect effects (Figure 1). Therefore, it could be recommended that, in an effort to improve risk management and project success in the UAE construction industry, the major focus should be on the management of issues related to cultural diversity rather than on general cultural matters (whose impacts are approximately two times weaker than that of cultural diversity - see equations (1) and (2)). The important issues in this regard correspond to the items with the largest factor loadings in the Cultural Diversity factor (Table 1), including the development and application of effective dispute-resolution procedures, addressing language diversity, diversified workplace cultures and differences in decision-making processes. 
AL hasani et al., Impacts of cultural risk factors on project success in the UAE construction Industry

\section{REFERENCES}

AECOM. (2016). Middle East Handbook: Property and Construction Handbook 2016 Edition. Retrieved 06/05/2017 from: http://www.aecom.com/ae/wp-content/uploads/2015/08/Handbook-2016-Final Lowresspreads.pdf

Al Ariss, A. and Guo, G. C. (2016). Job allocations as cultural sorting in a culturally diverse organizational context. International Business Review, 25(2), 579-588.

Al-Yahya, K. O. (2009). Power-influence in decision making, competence utilization, and organizational culture in public organizations: The Arab world in comparative perspective. Journal of Public Administration Research and Theory, 19(2), 385-407.

Assaf, S. A., and Al-Hejji, S. (2006). Causes of delay in large construction projects. International Journal of Project Management, 24(4), 349-357.

Deloitte. (2016). Deloitte GCC Powers of Construction 2016: The Funding Equation. Retrieved 17/09/2016 from: https://www2.deloitte.com/xe/en/pages/real-estate/articles/gcc-powers-of-construction-2016.html

Doloi, H., Sawhney, A., and Iuer, K. C. (2012). Structural equation model for investigating factors affecting delay in Indian construction projects, Construction Management and Economics. Construction Management and Economics, 30(10), 869-884.

El-Sayegh, S. M. (2008). Risk assessment and allocation in the UAE construction industry. International Journal of Project Management, 26(4), 431-438.

Eybpoosh, M., Dikmen, I., Birgonul, M. T. (2011). Identification of risk paths in international construction projects using structural equation modeling. Journal of Construction Engineering and Management, 137(12), 1164-1175.

Harvett, G. M. (2013). A study of uncertainty and risk management practice relative to perceived project complexity. Bond University, Gold Coast, Australia (PhD Thesis).

Hwang, B. G., Zhao, X., and Chin, E. W. Y. (2017). International construction joint ventures between Singapore and developing countries: Risk assessment and allocation preferences. Engineering Construction and Architectural Management, 24(2), 209-228.

Kim, D. Y., Han, S. H., Kim, H., and Park, H. (2009). Structuring the prediction model of project performance for international construction projects: A comparative analysis. Expert Systems with Applications, 36(8), 1961-1971.

Liu. J., Zhao, X., Yan, P. (2016). Risk paths in international construction projects: Case study from Chinese contractors. Journal of Construction Engineering and Management, 142(6), 1-16.

Loosemore, M., Raftery, J., Reily, C., and Higgon, D. (2006). Risk Management in Projects (2 ${ }^{\text {nd }}$ ed). Oxon: Taylor and Francis.

Odongo, E. K., Agneta, N., and Orinda, E. O. (2012). The impact of global cultural differences on the pricing strategies in United States of America. International Journal of Academic Research in Business and Social Science., 2(2), 58-68.

PMI. (2013). Project Management Body of Knowledge (PMBOK) (5 $\left.5^{\text {th }} e d.\right)$. Newton Square, Pennsylvania, USA: Project Management Institute (PMI), Inc.

Panthi, K., Ahmed, S. M., and Ogunlana, S. O. (2009). Contingency estimation for construction projects through risk analysis. International Journal of Construction Education and Research, 5(2), 79-94.

Randeree, K. and Chaudhry, A. G. (2012). Leadership - style, satisfaction and commitment: An exploration in the United Arab Emirates' construction sector. Engendering Construction and Architectural Management, 19(1), 61-85.

Rutherford, D. (2002). Routledge dictionary of economics ( $2^{\text {nd }}$ ed.). London, New York: Routledge.

Sambasivan, M., Deepak, T. J., Salim, A. N., Ponniah, V. (2017). Analysis of delays in Tanzanian construction industry. Engineering Construction and Architectural Management, 24(2), 308-325.

StataCorp. (2015). Stata Statistical Software: Release 14. College Station, TX: StataCorp LP.

Nunnally, J. C. (1967). Psychometric Theory. New York: McGraw Hill. 